\title{
Value of DCE-MRI and FDG-PET/CT in the prediction of response to preoperative chemotherapy with bevacizumab for colorectal liver metastases
}

\author{
S De Bruyne, 1,9, N Van Damme, ${ }^{2,9}$, P Smeets ${ }^{3}$, L Ferdinande ${ }^{4}$, W Ceelen², J Mertens ${ }^{5}$, C Van de Wiele ${ }^{5}$, R Troisi ${ }^{6}$, \\ L Libbrecht $^{4}$, S Laurent ${ }^{7}$, K Geboes ${ }^{*, 7}$ and M Peeters ${ }^{7,8}$ \\ 'Department of Respiratory Medicine, Ghent University Hospital, Ghent, Belgium; ²Department of Surgery, Ghent University Hospital, Ghent, Belgium; \\ ${ }^{3}$ Department of Radiology, Ghent University Hospital, Ghent, Belgium; ${ }^{4}$ Department of Pathology, Ghent University Hospital, Ghent, Belgium; \\ ${ }^{5}$ Department of Nuclear Medicine, Ghent University Hospital, Ghent, Belgium; ${ }^{6}$ Department of General and Hepato-Biliary Surgery, Ghent University \\ Hospital, Ghent, Belgium; ${ }^{7}$ Department of Gastroenterology, Ghent University Hospital, Ghent, Belgium; ${ }^{8}$ Department of Oncology, Antwerp University \\ Hospital, Edegem, Belgium
}

BACKGROUND: The purpose of this study was to assess the role of dynamic contrast-enhanced magnetic resonance imaging (DCE-MRI) and ${ }^{18}$ F-fluorodeoxyglucose positron emission tomography computed tomography (FDG-PET/CT) for evaluation of response to chemotherapy and bevacizumab and for prediction of progression-free survival (PFS) in patients with metastatic colorectal cancer ( $\mathrm{mCRC}$ ) with potentially resectable liver lesions.

METHODS: A total of 19 mCRC patients were treated with FOLFOX/FOLFIRI and bevacizumab followed by surgery. Dynamic contrast-enhanced magnetic resonance imaging and FDG-PET/CT were performed before treatment and after cycle 5. PET results were quantified by calculating maximum standardised uptake value ( $S \cup V_{\text {max }}$ ) whereas area under the enhancement curve (AUC), initial $A \cup C$ (iAUC) and the endothelial transfer constant $\left(K^{\text {trans }}\right)$ were used to quantify DCE-MRI. Pathological analysis of the resection specimen was performed, including measurement of microvessel density (MVD) and proliferation index.

RESULTS: Both AUC and iAUC were significantly decreased following bevacizumab therapy (median change of $22 \%(P=0.002)$ and $40 \%(P=0.001)$ for AUC and iAUC, respectively). Progression-free survival benefit was shown for patients with $>40 \%$ reduction in $K^{\text {trans }}(P=0.019)$. In the group of radiological responders, the median baseline SUV max was 3.77 (IQR: 2.88-5.60) compared with 7.20 (IQR: 4.67-8.73) in nonresponders $(P=0.021)$. A higher follow-up SUV $\max$ was correlated with worse PFS $(P=0.012)$. Median MVD was 10.9. Progression-free survival was significantly shorter in patients with an MVD greater than I0, compared with patients with lower MVD ( 10 months compared with 16 months, $P=0.016$ ).

CONCLUSION: High relative decrease in $\mathrm{K}^{\text {trans }}$, low follow-up SUV $\max$ and low MVD are favourable prognostic factors for mCRC patients treated with bevacizumab before surgery.

British Journal of Cancer (2012) 106, 1926-1933. doi:I0.1038/bjc.2012.I84 www.bjcancer.com

Published online 17 May 2012

(C) 2012 Cancer Research UK

Keywords: bevacizumab; colorectal cancer; DCE-MRI; FDG-PET/CT; immunohistochemistry; liver metastases

Colorectal cancer (CRC) is the second most common cause of cancer in women and the third most common in men, representing the fourth most common cause of cancer death after lung, stomach and liver cancer. It is more common in developed than in developing countries. The liver is the initial distant metastatic site in about $30 \%$ of patients (Leporrier et al, 2006). Complete surgical resection offers the best chance for cure in patients with liver metastases, with 5-year survival rates ranging from 21 to $33 \%$ (Scheele and Altendorf-Hofmann, 1999; Choti et al, 2002; Nordlinger et al, 2008).

Over the last decades, combined chemotherapy regimens including irinotecan and oxaliplatin have markedly improved the

\footnotetext{
*Correspondence: Dr K Geboes; E-mail: karen.geboes@uzgent.be

${ }^{9}$ These authors contributed equally to this work.

Received 31 October 2011; revised 29 March 2012; accepted 9 April 2012; published online 17 May 2012
}

response rate and survival. The addition of biological agents (anti-EGFR antibodies and anti-VEGF antibodies for example bevacizumab) to conventional chemotherapy increases overall survival in metastatic colorectal cancer (mCRC). Biological agents also improve response rates and subsequently enlarge the proportion of patients referred to surgery by rendering unresectable liver metastases resectable (Cunningham et al, 2004; Hurwitz et al, 2004; Gruenberger et al, 2008; Saltz et al, 2008; Chaudhury et al, 2010). With the use of perioperative strategies such as twostage hepatectomy, 5-year survival rates may increase from 31 to 50\% (Togo et al, 2005; Chun et al, 2007; Pamecha et al, 2008; Wicherts et al, 2008).

Response to bevacizumab, which exerts an anti-angiogenic action, may be inadequately assessed by traditional size-based radiologic criteria, the Response Evaluation Criteria In Solid Tumours (RECIST) (Therasse et al, 2000; Eisenhauer et al, 2009). They were designed for assessing tumour volume reduction following cytotoxic chemotherapy and only provide information 
on tumour anatomy. Therefore, the introduction of targeted therapies requires new tools for monitoring therapeutic effects focusing more on the physiology of the tumour (Rehman and Jayson, 2005; Shih and Lindley, 2006; de Langen et al, 2011; Mulder et al, 2011). Dynamic contrast-enhanced magnetic resonance imaging (DCE-MRI) is an attractive modality for evaluating anti-angiogenic cancer therapies such as bevacizumab, as the rapid acquisition of images before and after intravenous contrast media administration can be used to assess changes in tumour vasculature. Dynamic contrast-enhanced magnetic resonance imaging thus provides a new dimension in the assessment of tumour physiology. The utility of DCE-MRI has already been explored in animal experiments (Ceelen et al, 2006; Bauerle et al, 2010; Ellingsen et al, 2010; Casneuf et al, 2011) as well as in several clinical trials (Vriens et al, 2009; Hirashima et al, 2011; O'Connor et al, 2011), and it was suggested that DCE-MRI is useful as a pharmacodynamic biomarker (Morgan et al, 2003; Liu et al, 2005; Wedam et al, 2006; Jarnagin et al, 2009).

Molecular imaging with fluorodeoxyglucose positron emission tomography computed tomography (FDG-PET/CT) is useful in the management of CRC. Fluorodeoxyglucose positron emission tomography computed tomography already has a role in staging before surgical resection of locally recurrent cancer and metastases and in the assessment of residual masses after treatment. Nowadays, there is growing interest in the role of FDG-PET/CT for the prediction of tumour response to treatment, as metabolic alterations in tumour cells may occur before alterations in tumour size. Several studies indicated a possible role for FDG$\mathrm{PET} / \mathrm{CT}$ in the prediction and evaluation of treatment response (Langenhoff et al, 2002; Donckier et al, 2003; DimitrakopoulouStrauss et al, 2004; Guillem et al, 2004; Cascini et al, 2006; de Geus-Oei et al, 2008).

Both these imaging tools may be specifically adequate in the prediction of response to anti-angiogenetic therapies such as bevacizumab. Biological agents are expensive and thus tools for early prediction of response, allowing us to stop therapy in nonresponders, are needed. Moreover, there exists a need for tools to predict which patients will benefit from surgery after an initial response to chemotherapy.

The goal of this study was to prospectively evaluate the role of DCE-MRI and FDG-PET/CT for evaluation of response and for prediction of long-term outcome in patients with potentially resectable colorectal liver metastases treated with bevacizumab before surgery. In addition, histological parameters were analysed on resection specimens and their value for prediction of prognosis was also prospectively evaluated.

\section{PATIENTS AND METHODS}

\section{Patients}

All eligible patients with a diagnosis of CRC and potentially resectable liver metastases were treated with FOLFOX6 (oxaliplatin $100 \mathrm{mg} \mathrm{m}^{-2}$ per $2 \mathrm{~h}$, leucovorin $400 \mathrm{mg} \mathrm{m}^{-2}$ per $2 \mathrm{~h}, 5 \mathrm{FU}$ bolus $400 \mathrm{mg} \mathrm{m}^{-2}$ per $10 \mathrm{~min}$ and $5 \mathrm{FU}$ continuous infusion
$2400 \mathrm{mg} \mathrm{m}^{-2}$ per $46 \mathrm{~h}$ ) or FOLFIRI (irinotecan $180 \mathrm{mg} \mathrm{m}^{-2}$ per $90 \mathrm{~min}$, leucovorin $400 \mathrm{mg} \mathrm{m}^{-2}$ per $2 \mathrm{~h}, 5 \mathrm{FU}$ bolus $400 \mathrm{mg} \mathrm{m}^{-2}$ per $10 \mathrm{~min}$ and $5 \mathrm{FU}$ continuous infusion $2400 \mathrm{mg} \mathrm{m}^{-2}$ per $46 \mathrm{~h}$ ) and bevacizumab (Avastin, $5 \mathrm{mg} \mathrm{kg}^{-1}$ ) before surgical resection of the liver metastases (Figure 1). In total, 5 cycles (cycle duration, 14 days) were given. The fifth cycle was given without bevacizumab to avoid adverse events of bevacizumab such as surgical wound healing or bleeding complications. Carcinogen embryonic antigen (CEA) level was measured at baseline and at the end of chemotherapy.

Dynamic contrast-enhanced magnetic resonance imaging as well as FDG-PET/CT scans were performed before the start of chemotherapy. Pretreatment DCE-MRI scans were performed 4 (IQR: 3-8) days before start and FDG-PET/CT scans 12 (IQR: 8-20) days before therapy start. Follow-up DCE-MRI and FDG-PET/CT scans were acquired 15 days (IQR: 14-19 days) after the last cycle. In addition, a re-evaluation with DCE-MRI was performed after cycle 1 of chemotherapy (early follow-up). About 20 lesions in total could be used for lesion-by-lesion analysis.

The study was approved by the institutional review board of the Ghent University Hospital and written informed consent was obtained from each patient. About 19 patients were included in this prospective pilot study between September 2006 and April 2010. Patient characteristics are summarised in Table 1.

\section{Dynamic contrast-enhanced magnetic resonance imaging}

Dynamic contrast-enhanced magnetic resonance imaging scans were performed using a 1.5-T superconducting magnet (Magnetom Avanto, Siemens, Erlangen, Germany) with a phased-array body coil (for imaging acquisition and reconstructions: see Supplementary Materials).

The obtained data were imported into a dedicated commercially available software package (MiStar, Apollo Medical Imaging, Melbourne, Victoria, Australia) for further processing. To provide an arterial input function (AIF), a region-of-interest (ROI) was drawn in the middle of the aorta to minimise partial volume effect. For each visible lesion, ROIs were drawn manually to cover the entire perimeter of the metastases. The following parameters were calculated: area under the enhancement curve (AUC; using all 500 dynamic images), initial AUC (iAUC; AUC using the first 60 dynamic images) and $\mathrm{K}^{\text {trans }}$. To obtain the parametric maps of $\mathrm{K}^{\text {trans }}$, the signal intensity curves from both AIF and ROI were imported and fitted to the Tofts two-compartment model (Tofts et al, 1999) (Figure 2). Only the pixels with a goodness of fit (GOF) higher than 0.5 for this pharmacokinetic model were taken into account. Quantitative values for all pixels were exported to SPSS (SPSS Inc., Chicago, IL, USA) for further statistical analysis.

\section{Fluorodeoxyglucose positron emission tomography computed tomography imaging}

All examinations were performed according to the standard FDG-PET/CT protocol at the Department of Nuclear Medicine at the Ghent University Hospital. All image analyses were performed by an experienced nuclear medicine physician using the PMOD software (version 3.1, PMOD Technologies Ltd, Zürich, Switzerland).

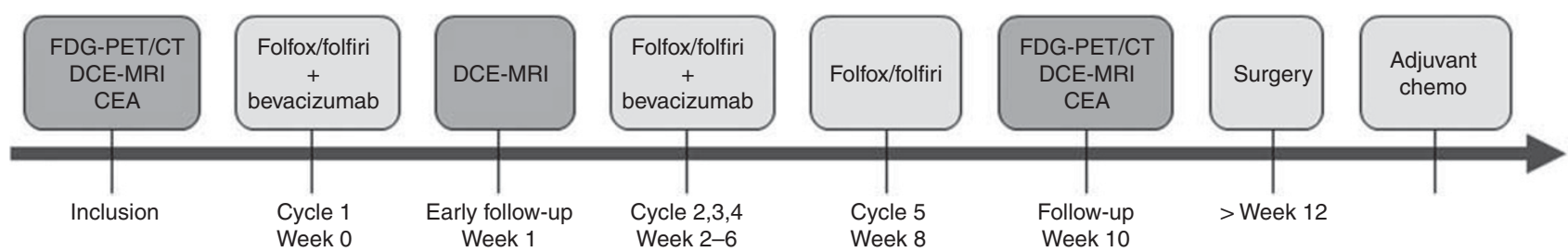

Figure I Flow chart of the study. 
Table I Patient characteristics

\begin{tabular}{|c|c|}
\hline Variable & $N=19(\%)$ \\
\hline \multicolumn{2}{|l|}{ Gender } \\
\hline Male & $12(63)$ \\
\hline Female & $7(37)$ \\
\hline Age & 61 \\
\hline \multicolumn{2}{|l|}{ Primary tumour location } \\
\hline Colon & $16(84)$ \\
\hline Rectum & $3(16)$ \\
\hline \multicolumn{2}{|l|}{ Synchronicity of liver metastases } \\
\hline Synchronous metastases & $7(37)$ \\
\hline Metachronous metastases & $11(58)$ \\
\hline No liver metastasis ${ }^{\mathrm{a}}$ & ( $(5)$ \\
\hline \multicolumn{2}{|c|}{ Previous chemotherapy for metastatic disease } \\
\hline Folfiri & । (5) \\
\hline Folfox & $3(16)$ \\
\hline Xeloda & । (5) \\
\hline Folfox + panitumumab & ( (5) \\
\hline None & $13(68)$ \\
\hline \multicolumn{2}{|l|}{ CEA $\left(n g m l^{-1}\right)$} \\
\hline$\leqslant 5$ & $5(26)$ \\
\hline$>5$ & $13(68)$ \\
\hline \multicolumn{2}{|c|}{ Chemotherapy before liver resection } \\
\hline Folfox + bevacizumab & $12(63)$ \\
\hline Folfiri + bevacizumab & $6(32)$ \\
\hline \multicolumn{2}{|c|}{ Postoperative chemotherapy for liver metastases } \\
\hline Folfox & $7(37)$ \\
\hline Folfiri & $4(21)$ \\
\hline None & $5(26)$ \\
\hline No liver resection & $3(16)$ \\
\hline \multicolumn{2}{|l|}{ Number of liver metastases } \\
\hline$\leqslant 3$ & $9(47)$ \\
\hline$>3$ & $9(47)$ \\
\hline \multicolumn{2}{|l|}{ Diameter of the largest lesion } \\
\hline$<5 \mathrm{~cm}$ & $12(63)$ \\
\hline$\geqslant 5 \mathrm{~cm}$ & $6(32)$ \\
\hline
\end{tabular}

Abbreviation: CEA = carcinogen embryonic antigen. ${ }^{\text {aScreening failure: this patient }}$ received the described chemotherapy regimen for treatment of extrahepatic metastases and was excluded for analysis of the results.

For imaging acquisition and reconstructions and details on image analysis: see Supplementary Materials. The metabolic response was defined by changes in FDG uptake in two liver target lesions, if available, as expressed by the maximum standardised uptake value $\left(S_{U} V_{\text {max }}\right)$ and was evaluated using the criteria of the European Organisation for Research and Treatment of Cancer (EORTC). Complete metabolic response (metabolic CR) was defined when there was complete resolution of the two target lesions. Partial metabolic response (PR) was defined as $>25 \%$ decrease in SUV $_{\text {max; }}$ progressive disease (PD) was characterised by $>25 \%$ increase in $\mathrm{SUV}_{\max }$ or the appearance of a new lesion. Metabolic responders consisted of $\mathrm{CR}$ and $\mathrm{PR}$.

\section{Hepatectomy}

Liver resection was done at a median of 48 days (IQR: 38-55) after the last administration of preoperative chemotherapy in patients with adequate liver function. Indication for surgery was always discussed with a multidisciplinary team. Type and extent of liver surgery with curative intent were finally decided by the liver surgeon. An oncological but parenchyma sparing resection strategy was considered in all cases with the aim to allow a further surgery in case of recurrence of mCRC. The resection was considered as R0 if the resection margins of the liver metastases were free of tumour cells. Two patients did not proceed to surgery owing to evolution of the disease and were therefore excluded from progression-free survival analysis.

\section{Pathologic examination}

To assess the tumouricidal effect of chemotherapy, routine hematoxylin-eosin-stained sections were reviewed by a blinded pathologist. The extent of residual carcinoma was scored semiquantitatively by estimating the proportion of residual cancer cells in relation to the total tumour area as previously described (Blazer et al, 2008). Microvessel density (MVD), an index of angiogenesis, was determined by immunohistochemical expression of CD31. Proliferation activity of cells was evaluated by the Ki-67 index. Immunohistochemical staining was performed on formalin-fixed, paraffin-embedded material of the resection specimen (for details see Supplementary Material available online).

\section{Patient follow-up}

Chemotherapy (without bevacizumab) was continued postoperatively as an adjuvant therapy (normally 7 cycles). The date of progression was defined as the earliest date of either progressive or recurrent disease, or death of any cause. Progression-free survival (PFS) was measured from the start date of chemotherapy until the initial date of progression. One patient did not develop progression while on study and the PFS was censored at the date of his last visit. The close-out date of the study was set at 31 July 2011.

\section{Statistical analysis}

Differences were assessed for significance by the Mann-Whitney $U$ test and by the Wilcoxon signed rank test for paired data. Correlations were determined by the nonparametric Spearman test. Cancer-related PFS was calculated using Kaplan-Meier estimates and were analysed by log-rank test. Univariate analyses were performed by the Cox proportional hazards model. All hypothesis tests were performed at the 5\% significance level, and were two-sided. Statistical analysis was done with SPSS (version 18, SPSS Inc.).

\section{RESULTS}

\section{Treatment response and survival}

One patient appeared to have no liver metastases and was therefore excluded for all further data analysis. According to RECIST, eight patients had a PR $(44.4 \%)$, nine patients had stable disease $(50 \%)$ and only one patient showed PD (5.6\%). Two patients did not proceed to surgery owing to evolution of the disease and were therefore excluded from progression-free survival analysis. Median PFS was 10 months and was identical for patients with and without anatomical response. At a median follow-up of 31 months (14-47 months), 15 of 16 operated patients developed disease progression. In 12 patients $(75 \%)$ the liver, either alone $(N=10)$ or in combination with the lungs $(N=2)$, was the initial site of progression; 3 patients (19\%) progressed initially at the lungs, one of them eventually had hepatic disease progression. During the follow-up period, seven patients died. The 2-year overall survival rate for the operated patients was $87 \%$ and 1 -year PFS was $44 \%$. At the close-out date, two patients were considered disease-free while nine patients were still on treatment.

The time between end of chemotherapy and surgery had a significant effect on PFS with an interval time $\leqslant 7$ weeks being favourable for PFS (14 months compared with 9 months, $P=0.013)$. None of the other patient or treatment characteristics had a significant effect on PFS (Table 2). 


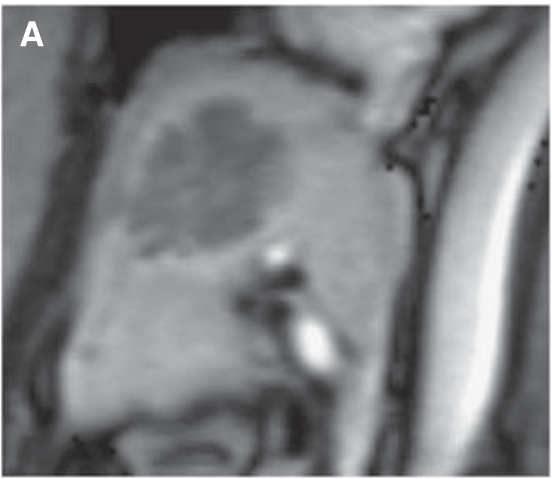

B
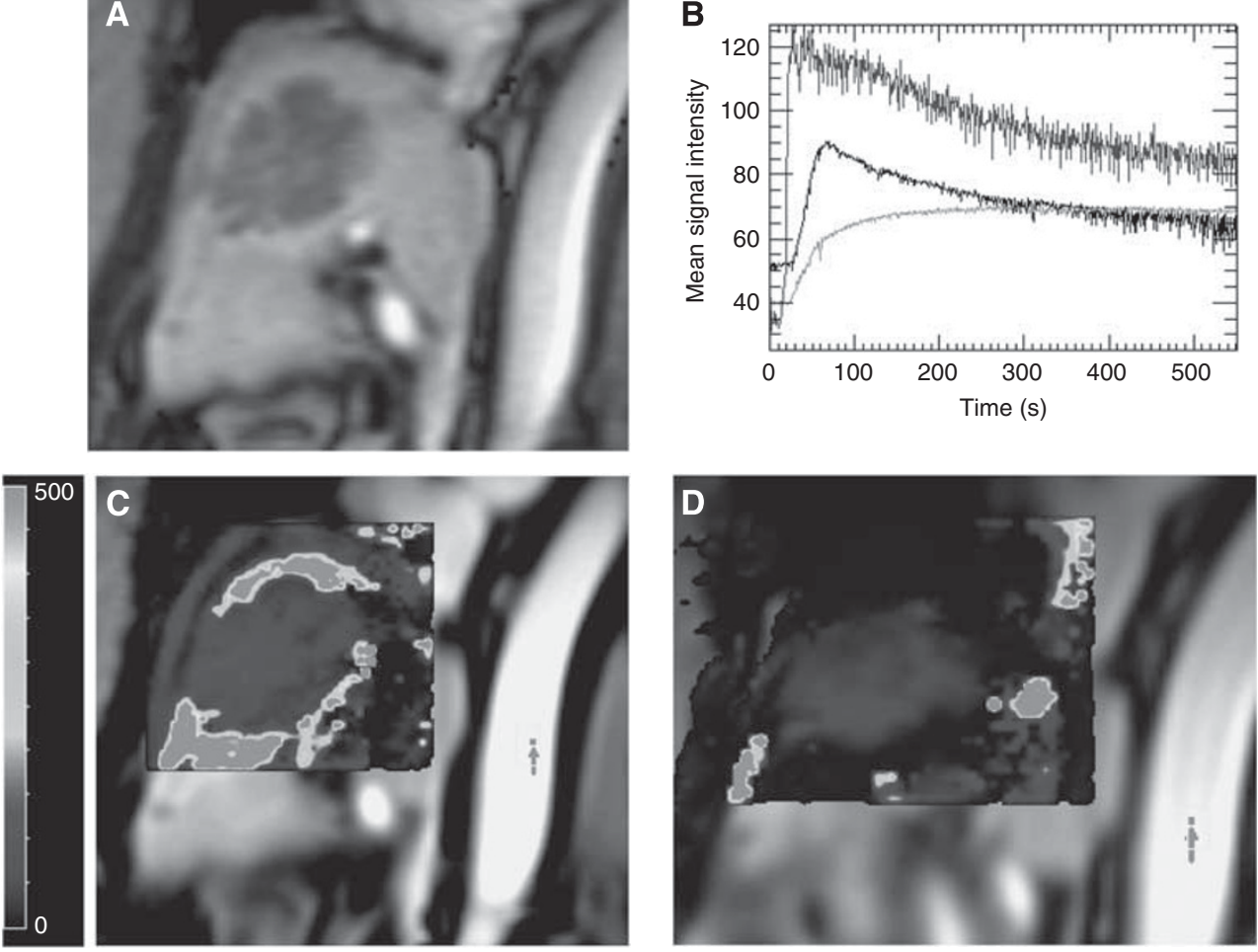

Figure 2 (A) Baseline MR image showing a large colorectal metastasis in the right liver lobe. (B) Signal intensity time course in regions of interest placed over the aorta (upper curve), normal liver parenchyma (middle curve) and tumour tissue (lower curve). (C) Parametric map of $K^{\text {trans }}$ ( $\mathrm{ml}-\mathrm{I} / \mathrm{I}$ 000) before therapy start. (D) Parametric map of $K^{\text {trans }}$ after I cycle of bevacizumab-containing chemotherapy. A clear effect is seen at the angiogenic tumour rim. The arrow points to the pixel (aorta) used as the arterial input for modelling.

Table 2 Results of Kaplan-Meier analysis for predicting PFS

\begin{tabular}{|c|c|c|c|c|}
\hline \multirow[b]{2}{*}{ Parameter } & \multirow[b]{2}{*}{ Group } & \multicolumn{3}{|c|}{ PFS } \\
\hline & & $\begin{array}{l}\text { Critical } \\
\text { events }\end{array}$ & $\begin{array}{c}\text { Median } \\
\text { (months) }\end{array}$ & $\begin{array}{c}\text { Log- } \\
\text { rank } \\
\text { test }\end{array}$ \\
\hline Sex & $\begin{array}{l}\text { Female } \\
\text { Male }\end{array}$ & $\begin{array}{l}6 / 6 \\
9 / 10\end{array}$ & $\begin{array}{l}12 \\
10\end{array}$ & 0.455 \\
\hline Age at start therapy & $\begin{array}{l}\leqslant 60 \\
>60\end{array}$ & $\begin{array}{l}8 / 8 \\
7 / 8\end{array}$ & $\begin{array}{l}12 \\
10\end{array}$ & 0.671 \\
\hline Chemotherapy & $\begin{array}{l}\text { FolFox } \\
\text { FolFiri }\end{array}$ & $\begin{array}{l}10 / 11 \\
5 / 5\end{array}$ & $\begin{array}{l}10 \\
12\end{array}$ & 0.810 \\
\hline Detection of liver metastasis & $\begin{array}{l}\text { Synchronous } \\
\text { Metachronous }\end{array}$ & $\begin{array}{l}6 / 6 \\
9 / 10\end{array}$ & $\begin{array}{l}12 \\
10\end{array}$ & 0.495 \\
\hline Chemonaive & $\begin{array}{l}\text { Yes } \\
\text { No }\end{array}$ & $\begin{array}{l}10 / 10 \\
5 / 6\end{array}$ & $\begin{array}{l}10 \\
10\end{array}$ & 0.928 \\
\hline Number of liver lesions & $\begin{array}{l}\leqslant 3 \\
>3\end{array}$ & $\begin{array}{l}7 / 8 \\
8 / 8\end{array}$ & $\begin{array}{l}10 \\
10\end{array}$ & 0.266 \\
\hline Diameter of the largest lesion & $\begin{array}{l}<5 \mathrm{~cm} \\
\geqslant 5 \mathrm{~cm}\end{array}$ & $\begin{array}{l}12 / 12 \\
3 / 4\end{array}$ & $\begin{array}{l}10 \\
11\end{array}$ & 0.177 \\
\hline Primary tumour location & $\begin{array}{l}\text { Colon } \\
\text { Rectum }\end{array}$ & $\begin{array}{l}13 / 14 \\
2 / 2\end{array}$ & $\begin{array}{l}10 \\
11\end{array}$ & 0.732 \\
\hline RO resection liver metastases & $\begin{array}{l}\text { Yes } \\
\text { No }\end{array}$ & $\begin{array}{l}12 / 13 \\
3 / 3\end{array}$ & $\begin{array}{l}11 \\
10\end{array}$ & 0.267 \\
\hline Liver-only metastases & $\begin{array}{l}\text { Yes } \\
\text { No }\end{array}$ & $\begin{array}{l}13 / 14 \\
2 / 2\end{array}$ & $\begin{array}{r}11 \\
6\end{array}$ & 0.064 \\
\hline $\begin{array}{l}\text { Time between last } \\
\text { chemotherapy and surgery }\end{array}$ & $\begin{array}{l}\leqslant 7 \text { weeks } \\
>7 \text { weeks }\end{array}$ & $\begin{array}{l}9 / 10 \\
6 / 6\end{array}$ & $\begin{array}{r}14 \\
9\end{array}$ & 0.013 \\
\hline
\end{tabular}

Abbreviation: PFS = progression-free survival. The bold value indicates statistical significance.

\section{Dynamic contrast-enhanced magnetic resonance imaging}

In two patients, DCE-MRI data were not complete: one patient did not undergo DCE-MRI after 5 therapy cycles and in another patient the lesion was too small to identify on the follow-up scan.
Changes in DCE-MRI parameters upon treatment with bevacizumab At baseline, there was a strong correlation between AUC and iAUC $(r=0.841, P<0.001)$, a less pronounced correlation between $\mathrm{K}^{\text {trans }}$ and AUC $(r=0.549, P=0.01)$ and no correlation between $\mathrm{K}^{\text {trans }}$ and iAUC.

Both AUC and iAUC were significantly decreased after the first cycle of chemotherapy (Figure 3). For AUC, the decrease continued at the follow-up scan. For both measured parameters, a greater change was observed from baseline to the early follow-up scan (median decrease 18\% $(P=0.003)$ and $40 \%(P=0.002)$ for AUC and iAUC, respectively) than from early follow-up to follow-up (median change 9\% $(P>0.05)$ and $0 \%(P>0.05)$ for AUC and iAUC, respectively). The median $\mathrm{K}^{\text {trans }}$ on the other hand increased upon treatment with bevacizumab (median $\mathrm{K}^{\text {trans }}$ of 34,49 and $65.5 \mathrm{~min}^{-1}$ per 1000 at baseline, after cycle 1 and at the end of chemotherapy, respectively) but this effect was not significant (Figure 3C).

The pre- and post-treatment AUC, iAUC and $\mathrm{K}^{\text {trans }}$ did not differ significantly between the patients with and those without anatomical response neither between metabolic responders and nonresponders.

Survival Pretreatment AUC, iAUC and $\mathrm{K}^{\text {trans }}$ were not predictive for survival. Regarding changes from pretreatment to follow-up scans, $\mathrm{K}^{\text {trans }}$ revealed a survival correlation. If $\Delta \mathrm{K}^{\text {trans }}$ was dichotomised around the median, a trend towards survival benefit was seen for a higher reduction in $\mathrm{K}^{\text {trans }}$ at both the early $(P=0.086)$ and the late follow-up scan $(P=0.091)$. Further exploration of the data showed that patients with an increase $>40 \%$ at their early follow-up scan showed a significantly worse survival (9 months vs 14 months) than patients with an increase $\leqslant 40 \%$ in $\mathrm{K}^{\text {trans }}(P=0.026)$ (Figure $\left.4 \mathrm{~A}\right)$. Moreover, compared with baseline, a decrease of $\mathrm{K}^{\text {trans }} \leqslant 40 \%$ on the follow-up scan was 
A

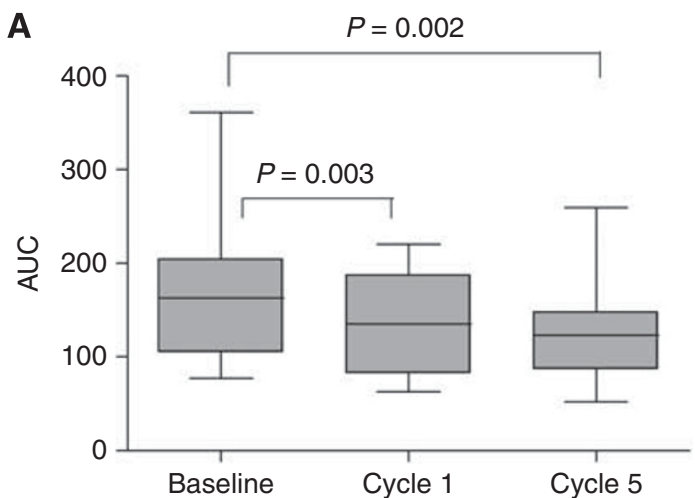

B
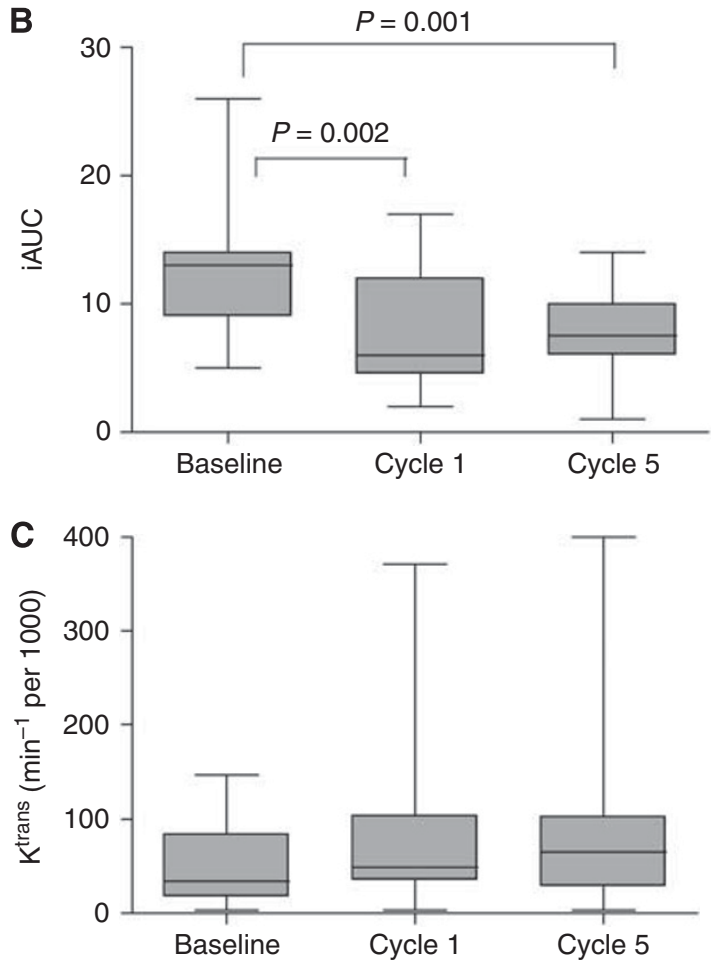

Figure 3 Median values of $A \cup C(\mathbf{A})$, iAUC $(\mathbf{B})$ and $K^{\text {trans }}(\mathbf{C})$ at each time point. Two-sided $P$-values were calculated with the Wilcoxon signed rank test. Significant $P$-values are reported.

associated with a PFS of 10 months compared with a PFS of 16 months wen $\mathrm{K}^{\text {trans }}$ decreased more than $40 \% \quad(P=0.019)$ (Figure 4B).

\section{Fluorodeoxyglucose positron emission tomography computed tomography}

Changes of metabolic activity during chemotherapy The median SUV $_{\max }$ at baseline varied between 2.59 and 10.06 (median $5.18) \mathrm{g} \mathrm{ml}^{-1}$. In the group of radiological responders, the median baseline $\mathrm{SUV}_{\max }$ was $3.77 \mathrm{~g} \mathrm{ml}^{-1}$ (IQR: 2.88-5.60) compared with $7.20 \mathrm{~g} \mathrm{ml}^{-1}$ (IQR: $\left.4.67-8.73\right)$ in nonresponders $(P=0.021)$. For the group of PET responders, the median baseline $S_{\text {SUax }}$ was $4.78 \mathrm{~g} \mathrm{ml}^{-1}$ (3.35-8.58) compared with $5.57 \mathrm{~g} \mathrm{ml}^{-1}$ (4.33-7.24) in PET nonresponders $(P=0.892)$. The median change at the follow-up scan compared with baseline was $25.25 \%$ (IQR: 6.16 to $60.89 \%$ ). This reduction in $\mathrm{SUV}_{\max }$ upon chemotherapy (from median 5.18 to median $2.97 \mathrm{~g} \mathrm{ml}^{-1}$ ) was statistically significant $(P=0.031)$. Figure 5 shows an example of a metabolic responder and a metabolic nonresponder.
The relationship between radiological and metabolic response is presented in Table 3. In total, six of eight patients with radiological response had metabolic response (sensitivity 75\%). About 5 of 10 patients with radiological nonresponse had no metabolic response (specificity $50 \%$ ).

Survival Patients with a metabolic CR had a significantly longer PFS (14 months) than those without (9 months, $P=0.003)$ (Figure 4C). For patients with metabolic response (CR or PR), median PFS was 12 months, whereas PFS was 10 months for patients without metabolic response $(P=0.202)$. The 1-year PFS rates for PET responders and PET nonresponders were 55 and $20 \%$, respectively. Within the PET responders, the 1-year PFS was the highest for the anatomical responders $(66 \%$ compared with $50 \%$ ).

Using univariate analysis, the follow-up $\mathrm{SUV}_{\max }$ showed a trend for a worse survival with higher $S_{\text {UUt }}$ (HR 1.196, 95\% CI $0.926-1.543, \quad P=0.170)$. The Kaplan-Meier survival analysis indicated the value of the follow-up $S U V_{\max }$ to predict survival. If the follow-up $S_{U V} V_{\max }$ was dichotomised at the median value $\left(2.85 \mathrm{~g} \mathrm{ml}^{-1}\right)$, higher $\mathrm{SUV}_{\max }$ was correlated with worse PFS (10 months compared with 14 months, $P=0.012$ ). The 1 -year PFS for a $S U V_{\max } \leqslant 2.85 \mathrm{~g} \mathrm{ml}^{-1}$ and a $S U V_{\max }$ higher than $2.85 \mathrm{~g} \mathrm{ml}^{-1}$ were $87.5 \%$ and $12.5 \%$, respectively.

\section{Carcinogen embryonic antigen}

Median CEA after chemotherapy $\left(8.18 \mathrm{ng} \mathrm{ml}^{-1}\right)$ was significantly lower compared with CEA at baseline $\left(20.95 \mathrm{ng} \mathrm{ml}^{-1}\right)(P=0.008)$. A decrease in CEA was seen in 12 patients while an increase was observed in 4 patients. Of those four patients, three showed PD either metabolically (according to EORTC criteria) or anatomically (according to RECIST).

Hepatectomy and immunohistochemistry In one patient, bleeding during surgery occurred. No other adverse event such as difficult resection or bowel perforation, was seen during surgery.

Complete pathological response was not observed. Major and minor pathological responses were seen in eight patients.

In two patients, the formalin-fixed, paraffin-embedded tumour material was unsuitable for analysis. Median MVD was 10.9. Progression-free survival was significantly shorter in patients with an MVD greater than 10, compared with patients with lower MVD (10 months compared with 16 months, $P=0.016$ ) (Figure 4D).

Proliferation activity of cancer wells was evaluated by the Ki-67 index. Ki-67 values of $50 \%$ or more and $80 \%$ or more were detected in 13/14 (93\%) and 4/14 (29\%) tumours, respectively. No survival benefit could be detected for tumours with lower Ki-67.

\section{DISCUSSION}

Angiogenesis inhibition remains a promising approach for the development of anticancer therapies. Bevacizumab has already shown to be effective and generally well tolerated in mCRC (Hurwitz et al, 2004). As bevacizumab treatment results are not predominantly cytoreductive, RECIST is less adequate to predict treatment efficacy. Therefore, we assessed the role of DCE-MRI and FDG-PET/CT for prediction of prognosis in mCRC patients treated with bevacizumab followed by surgery, next to some classical parameters.

A major finding of the present study was the delineation of a potentially important role of DCE-MRI in predicting outcome, both early during treatment and after treatment. An increase in $\mathrm{K}^{\text {trans }}$ of at least $40 \%$ after cycle 1 directly correlated with worse PFS. A decrease of more than $40 \%$ at the follow-up scan was associated with a better PFS. These findings are in agreement with 

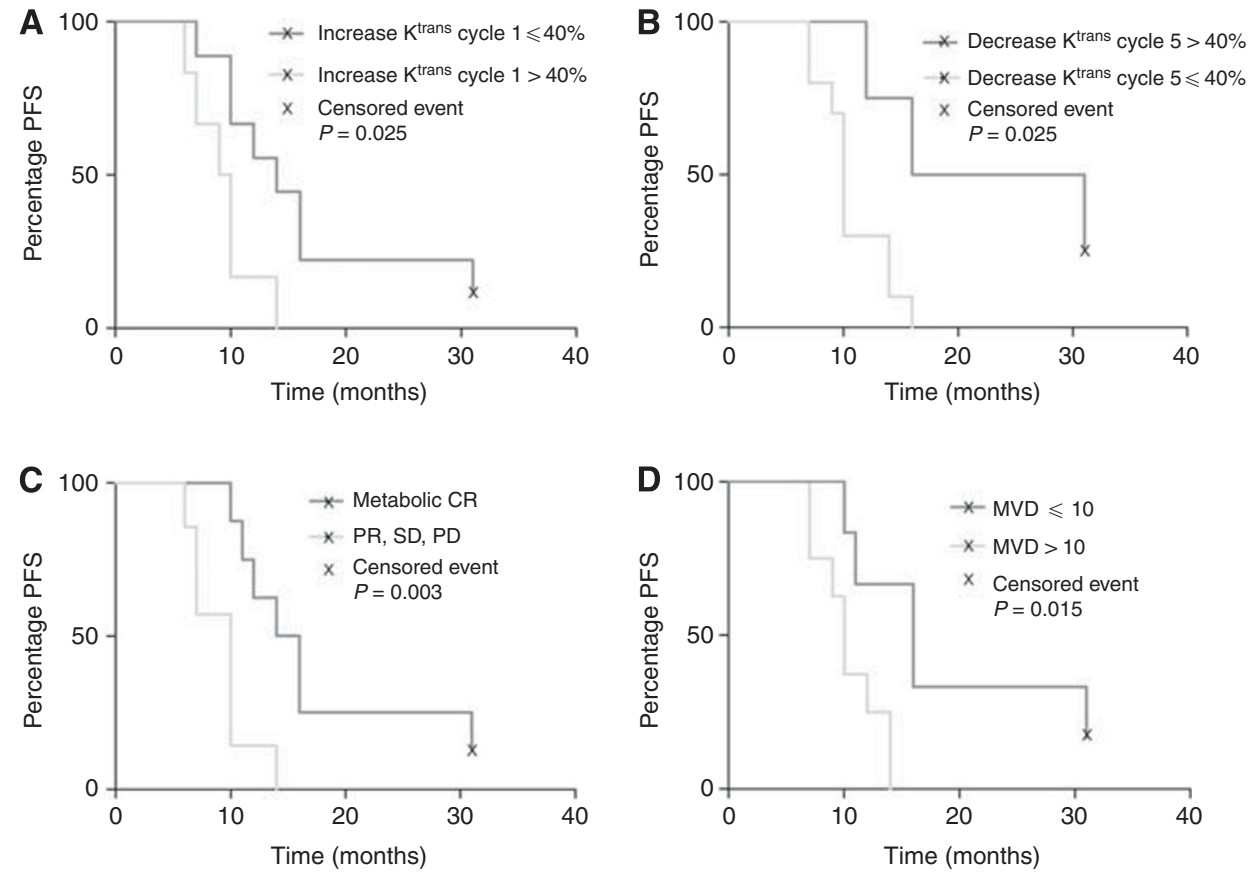

Figure 4 Cumulative progression-free survival rates stratified by $\Delta K^{\text {trans }}$ after I cycle of chemotherapy $(\mathbf{A}), \Delta K^{\text {trans }}$ at the end of chemotherapy $(\mathbf{B})$, metabolic CR (C) and MVD (D).

A

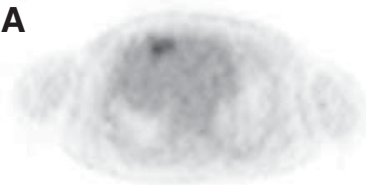

B
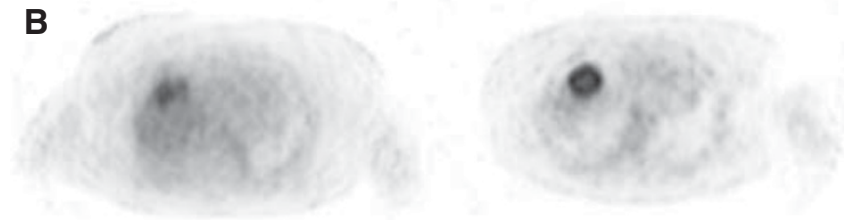

Figure 5 FDG-PET images of a metabolic responder $(\mathbf{A})$ and nonresponder (B) before and after chemotherapy.

Table 3 Correlation between metabolic response (FDG-PET/CT) and anatomical response

\begin{tabular}{lccccc}
\hline & \multicolumn{4}{c}{ Metabolic response } \\
\cline { 2 - 4 } Anatomical response & CR & PR & SD & PD & Total \\
\hline CR & 0 & 0 & 0 & 0 & 0 \\
PR & 5 & 1 & 0 & 2 & 8 \\
SD & 3 & 2 & 3 & 1 & 9 \\
PD & 0 & 0 & 1 & 0 & 1 \\
Total & 8 & 3 & 4 & 3 & 18 \\
\hline
\end{tabular}

Abbreviations: $C R=$ complete response; FDG-PET/CT $={ }^{18} \mathrm{~F}$-fluorodeoxyglucose positron emission tomography computed tomography; $\mathrm{PR}=$ partial response; $\mathrm{SD}=$ stable disease; $\mathrm{PD}=$ progressive disease

the results of certain trials (Flaherty et al, 2008; Hirashima et al, 2011). Hirashima also demonstrated a relationship between PFS and $\Delta \mathrm{K}^{\text {trans }}$, on the basis of DCE-MRI scans scheduled at other time points in the treatment than in our trial. Other studies did not establish a relationship between $\Delta \mathrm{K}^{\text {trans }}$ and survival (Vriens et al,
2009; de Langen et al, 2011; Li et al, 2011). In contrast with $\mathrm{K}^{\text {trans }}$, iAUC had no correlation with PFS. It is known, however, that compared with parameters calculated using compartmental models, heuristic (semiquantitative) parameters suffer from several limitations (Leach et al, 2005). These limitations include the fact that semiquantitative parameters do not accurately reflect contrast agent concentrations in the tissue of interest, do not have any physiological significance and are influenced by a variety of factors including the injection procedure, scanner model and settings (pulse sequence, gain and scaling factors), and target position in the image.

In a retrospective study, O'Connor et al (2011), using kinetic modelling of DCE-MRI data, showed that tumour shrinkage following treatment with FolFox and bevacizumab could be predicted on the basis of a combination of three variables (median extravascular extracellular volume, tumour enhancing fraction and microvascular uniformity) measured at baseline. It is very well possible that parameters at baseline DCE-MRI are better predictors for survival than parameters measured at scans during follow-up.

Baseline FDG-PET predicted the probability of an objective response, but not the probability of a metabolic response. This was also noted by Bystrom et al (2009). Complete metabolic responders had a significantly better PFS. In addition, we demonstrated that higher FDG uptake at follow-up scan correlated with worse PFS, in accordance to the study of Riedl et al (2007). Hence, our data indicate that after neoadjuvant chemotherapy, high glucose metabolism in liver metastases of CRC is a negative prognostic marker.

In our study, we did not find a correlation between DCE-MRI parameters and the standardised FDG uptake value, which is in agreement with several other studies (Vriens et al, 2009; Bisdas et al, 2010). The lack of correlation between DCE-MRI parameters, anatomical tumour response and $\mathrm{SUV}_{\max }$ suggests that tumour blood flow, tumour shrinkage and tumour glucose metabolism are potentially independent predictors of outcome and that both imaging techniques may provide complementary information.

The time between end of chemotherapy and surgery had a significant effect on PFS. When this time difference was entered as a categorical covariate in survival analysis of the imaging 
parameters, both $\Delta \mathrm{K}^{\text {trans }}$ and $\mathrm{SUV}_{\max }$ remained significantly predictive for PFS.

Association between CEA level and response was evaluated. There was a statistically significant reduction in CEA level in both metabolic and anatomical responders, and a slight but nonsignificant decrease in CEA level in both nonresponder groups (data not shown). As demonstrated by previous studies, tumour angiogenesis, measured by MVD, had a marked impact on prognosis in patients with radical hepatectomy; high MVD was significantly associated with shorter PFS in metastatic liver lesions of CRC (Nanashima et al, 1998; Nanashima et al, 2001; Miyagawa et al, 2002; Nanashima et al, 2009). In accordance, we demonstrated that low MVD of the liver metastases is a favourable prognostic factor.

In summary, high relative decrease in $\mathrm{K}^{\text {trans }}$, low follow-up $\mathrm{SUV}_{\text {max }}$, complete metabolic response and low MVD are favourable prognostic factors for mCRC patients who underwent liver surgery with curative intent after neoadjuvant chemotherapy with bevacizumab.

Some limitations of this study should be considered. The included population was small and heterogeneous. Furthermore,

\section{REFERENCES}

Bauerle T, Bartling S, Berger M, Schmitt-Graff A, Hilbig H, Kauczor HU, Delorme S, Kiessling F (2010) Imaging anti-angiogenic treatment response with DCE-VCT, DCE-MRI and DWI in an animal model of breast cancer bone metastasis. Eur J Radiol 73(2): 280-287

Bisdas S, Seitz O, Middendorp M, Chambron-Pinho N, Bisdas T, Vogl TJ, Hammerstingl R, Ernemann U, Mack MG (2010) An exploratory pilot study into the association between microcirculatory parameters derived by MRI-based pharmacokinetic analysis and glucose utilization estimated by PET-CT imaging in head and neck cancer. Eur Radiol 20(10): 2358-2366

Blazer DG, Kishi Y, Maru DM, Kopetz S, Chun YS, Overman MJ, Fogelman D, Eng C, Chang DZ, Wang H, Zorzi D, Ribero D, Ellis LM, Glover KY, Wolff RA, Curley SA, Abdalla EK, Vauthey JN (2008) Pathologic response to preoperative chemotherapy: a new outcome end point after resection of hepatic colorectal metastases. J Clin Oncol 26(33): 5344-5351

Bystrom P, Berglund A, Garske U, Jacobsson H, Sundin A, Nygren P, Frodin JE, Glimelius B (2009) Early prediction of response to first-line chemotherapy by sequential F-18 -2-fluoro-2-deoxy-D-glucose positron emission tomography in patients with advanced colorectal cancer. Ann Oncol 20(6): 1057-1061

Cascini GL, Avallone A, Delrio P, Guida C, Tatangelo F, Marone P, Aloj L, De Martinis F, Comella P, Parisi V, Lastoria S (2006) F-18-FDG PET is an early predictor of pathologic tumor response to preoperative radiochemotherapy in locally advanced rectal cancer. J Nucl Med 47(8): $1241-1248$

Casneuf VF, Delrue L, Van Damme N, Demetter P, Robert P, Corot C, Duyck P, Ceelen W, Boterberg T, Peeters M (2011) Noninvasive monitoring of therapy-induced microvascular changes in a pancreatic cancer model using dynamic contrast-enhanced magnetic resonance imaging with P846, a new low-diffusible gadolinium-based contrast agent. Radiat Res 175(1): 10-20

Ceelen W, Smeets P, Backes W, Van Damme N, Boterberg T, Demetter P, Bouckenooghe I, De Visschere M, Peeters M, Pattyn P (2006) Noninvasive monitoring of radiotherapy-induced microvascular changes using dynamic contrast enhanced magnetic resonance imaging (DCE$\mathrm{MRI}$ ) in a colorectal tumor model. Int J Radiat Oncol Biol Phys 64(4): 1188-1196

Chaudhury P, Hassanain M, Bouganim N, Salman A, Kavan P, Metrakos P (2010) Perioperative chemotherapy with bevacizumab and liver resection for colorectal cancer liver metastasis. $H p b$ 12(1): 37-42

Choti MA, Sitzmann JV, Tiburi MF, Sumetchotimetha W, Rangsin R, Schulick RD, Lillemoe KD, Yeo CJ, Cameron JL (2002) Trends in longterm survival following liver resection for hepatic colorectal metastases. Ann Surg 235(6): 759-765

Chun YS, Vauthey JN, Ribero D, Donadon M, Mullen JT, Eng C, Madoff DC, Chang DZ, Ho L, Kopetz S, Wei SH, Curley SA, Abdalla EK (2007) patients were allowed to breath normally during imaging acquisition, introducing movement artifacts. As a consequence, modelling failures can arise, for example, the Tofts model is not adequate in necrotic areas. To minimise this burden, only $\mathrm{K}^{\text {trans }}$ values with GOF $>0.5$ are taken into account. It is also important to emphasise that the liver has two blood supplies while the Tofts model only takes into account the AIF, the predominant blood supply of liver metastases.

Further studies should assess the impact of liver resection on PFS in patients with a high relative decrease in $\mathrm{K}^{\text {trans }}$ or no complete metabolic response in order to determine if these patients should proceed to surgery.

\section{ACKNOWLEDGEMENTS}

This work was supported by an unrestricted educational grant from Roche and by the Belgian National Cancer Plan (NKP29/026).

Supplementary Information accompanies the paper on British Journal of Cancer website (http://www.nature.com/bjc)
Systemic chemotherapy and two-stage hepatectomy for extensive bilateral colorectal liver metastases: perioperative safety and survival. J Gastrointest Surg 11(11): 1498-1504

Cunningham D, Humblet Y, Siena S, Khayat D, Bleiberg H, Santoro A, Bets D, Mueser M, Harstrick A, Verslype C, Chau I, Van Cutsem E (2004) Cetuximab monotherapy and cetuximab plus irinotecan in irinotecanrefractory metastatic colorectal cancer. New Engl J Med 351(4): $337-345$

de Geus-Oei LF, van Laarhoven HWM, Visser EP, Hermsen R, van Hoorn BA, Kamm YJL, Krabbe PFM, Corstens FHM, Punt CJA, Oyen WJG (2008) Chemotherapy response evaluation with FDG-PET in patients with colorectal cancer. Ann Oncol 19(2): 348-352

de Langen AJ, van den Boogaart V, Lubberink M, Backes WH, Marcus JT, van Tinteren $\mathrm{H}$, Pruim J, Brans B, Leffers P, Dingemans AMC, Smit EF, Groen HJM, Hoekstra OS (2011) Monitoring response to antiangiogenic therapy in non-small cell lung cancer using imaging markers derived from PET and dynamic contrast-enhanced MRI. J Nucl Med 52(1): 48-55

Dimitrakopoulou-Strauss A, Strauss LG, Burger C, Ruhl A, Irngartinger G, Stremmel W, Rudi J (2004) Prognostic aspects of F-18-FDG PET kinetics in patients with metastatic colorectal carcinoma receiving FOLFOX chemotherapy. J Nucl Med 45(9): 1480-1487

Donckier V, Van Laethem JL, Goldman S, Van Gansbeke D, Feron P, Ickx B, Wikler D, Gelin M (2003) F-18 fluorodeoxyglucose positron emission tomography as a tool for early recognition of incomplete tumor destruction after radiofrequency ablation for liver metastases. J Surg Oncol 84(4): 215-223

Eisenhauer EA, Therasse P, Bogaerts J, Schwartz LH, Sargent D, Ford R, Dancey J, Arbuck S, Gwyther S, Mooney M, Rubinstein L, Shankar L, Dodd L, Kaplan R, Lacombe D, Verweij J (2009) New response evaluation criteria in solid tumours: Revised RECIST guideline (version 1.1). Eur J Cancer 45(2): 228-247

Ellingsen C, Egeland TA, Galappathi K, Rofstad EK (2010) Dynamic contrast-enhanced magnetic resonance imaging of human cervical carcinoma xenografts: pharmacokinetic analysis and correlation to tumor histomorphology. Radiother Oncol 97(2): 217-224

Flaherty TK, Rosen AM, Heitjan FD, Gallagher LM, Schwartz B, Schnall MD, O'Dwyer JP (2008) Pilot study of DCE-MRI to predict progressionfree survival with sorafenib therapy in renal cell carcinoma. Canc Biol Ther 7(4): 496-501

Gruenberger B, Tamandl D, Schueller J, Scheithauer W, Zielinski C, Herbst F, Gruenberger T (2008) Bevacizumab, capecitabine, and oxaliplatin as neoadjuvant therapy for patients with potentially curable metastatic colorectal cancer. J Clin Oncol 26(11): 1830-1835

Guillem JG, Moore HG, Akhurst T, Klimstra DS, Ruo L, Mazumdar M, Minsky BD, Saltz L, Wong WD, Larson S (2004) Sequential preoperative fluorodeoxyglucose-positron emission tomography assessment of 
response to preoperative chemoradiation: a means for determining longterm outcomes of rectal cancer. J Am Coll Surgeons 199(1): 1-7

Hirashima Y, Yamada Y, Tateishi U, Kato K, Miyake M, Horita Y, Akiyoshi K, Takashima A, Okita N, Takahari D, Nakajima T, Hamaguchi T, Shimada Y, Shirao K (2011) Pharmacokinetic parameters from 3-Tesla DCE-MRI as surrogate biomarkers of antitumor effects of bevacizumab plus FOLFIRI in colorectal cancer with liver metastasis. Int $J$ Cancer 130(10): 2359-2365

Hurwitz H, Fehrenbacher L, Novotny W, Cartwright T, Hainsworth J, Heim W, Berlin J, Baron A, Griffing S, Holmgren E, Ferrara N, Fyfe G, Rogers B, Ross R, Kabbinavar F (2004) Bevacizumab plus irinotecan, fluorouracil, and leucovorin for metastatic colorectal cancer. New Engl J Med 350(23): 2335-2342

Jarnagin WR, Schwartz LH, Gultekin DH, Gonen M, Haviland D, Shia J, D’Angelica M, Fong Y, DeMatteo R, Tse A, Blumgart LH, Kemeny N (2009) Regional chemotherapy for unresectable primary liver cancer: results of a phase II clinical trial and assessment of DCE-MRI as a biomarker of survival. Ann Oncol 20(9): 1589-1595

Langenhoff BS, Oyen WJG, Jager GJ, Strijk SP, Wobbes T, Corstens FHM, Ruers TJM (2002) Efficacy of fluorine-18-deoxyglucose positron emission tomography in detecting tumor recurrence after local ablative therapy for liver metastases: a prospective study. J Clin Oncol 20(22): 4453-4458

Leach MO, Brindle KM, Evelhoch JL, Griffiths JR, Horsman MR, Jackson A, Jayson GC, Judson IR, Knopp MV, Maxwell RJ, McIntyre D, Padhani AR, Price P, Rathbone R, Rustin GJ, Tofts PS, Tozer GM, Vennart W, Waterton JC, Williams SR, Workman P (2005) Pharmacodynamic/ Pharmacokinetic Technologies Advisory Committee, Drug Development Office, Cancer Research UK. The assessment of antiangiogenic and antivascular therapies in early-stage clinical trials using magnetic resonance imaging: issues and recommendations. $\mathrm{Br} J$ Cancer 92(9): 1599-1610

Leporrier J, Maurel J, Chiche L, Bara S, Segol P, Launoy G (2006) A population-based study of the incidence, management and prognosis of hepatic metastases from colorectal cancer. Brit J Surg 93(4): 465-474

Li SP, Makris A, Beresford MJ, Taylor NJ, Ah-See MLW, Stirling JJ, d'Arcy JA, Collins DJ, Kozarski R, Padhani AR (2011) Use of dynamic contrast-enhanced MR imaging to predict survival in patients with primary breast cancer undergoing neoadjuvant chemotherapy. Radiology 260(1): 68-78

Liu G, Rugo HS, Wilding G, McShane TM, Evelhoch JL, Ng C, Jackson E, Kelcz F, Yeh BM, Lee FT, Charnsangavej C, Park JW, Ashton EA, Steinfeldt HM, Pithavala YK, Reich SD, Herbst RS (2005) Dynamic contrast-enhanced magnetic resonance imaging as a pharmacodynamic measure of response after acute dosing of AG-013736, an oral angiogenesis inhibitor, in patients with advanced solid tumors: results from a phase I study. J Clin Oncol 23(24): 5464-5473

Miyagawa S, Miwa S, Soeda J, Kobayashi A, Kawasaki S (2002) Morphometric analysis of liver macrophages in patients with colorectal liver metastasis. Clin Exp Metastasis 19(2): 119-125

Morgan B, Thomas AL, Drevs J, Hennig J, Buchert M, Jivan A, Horsfield MA, Mross K, Ball HA, Lee L, Mietlowski W, Fuxius S, Unger C, O’Byrne K, Henry A, Cherryman GR, Laurent D, Dugan M, Marme D, Steward WP (2003) Dynamic contrast-enhanced magnetic resonance imaging as a biomarker for the pharmacological response of PTK787/ZK 222584, an inhibitor of the vascular endothelial growth factor receptor tyrosine kinases, in patients with advanced colorectal cancer and liver metastases: results from two phase I studies. J Clin Oncol 21(21): 3955-3964

Mulder K, Scarfe A, Chua N, Spratlin J (2011) The role of bevacizumab in colorectal cancer: understanding its benefits and limitations. Expert Opin Biol Ther 11(3): 405-413

Nanashima A, Ito M, Sekine I, Naito S, Yamaguchi H, Nakagoe T, Ayabe H (1998) Significance of angiogenic factors in liver metastatic tumors originating from colorectal cancers. Digest Dis Sci 43(12): 2634-2640

Nanashima A, Shibata K, Nakayama T, Tobinaga S, Araki M, Kunizaki M, Takeshita H, Hidaka S, Sawai T, Nagayasu T, Yasutake T (2009) Clinical significance of microvessel count in patients with metastatic liver cancer originating from colorectal carcinoma. Ann Surg Oncol 16(8): 2130-2137

Nanashima A, Yamaguchi H, Sawai T, Yamaguchi E, Kidogawa H, Matsuo S, Yasutake T, Tsuji T, Jibiki M, Nakagoe T, Ayabe H (2001) Prognostic factors in hepatic metastases of colorectal carcinomaImmunohistochemical analysis of tumor biological factors. Digest Dis Sci 46(8): 1623-1628

Nordlinger B, Sorbye H, Glimelius B, Poston GJ, Schlag PM, Rougier P, Bechstein WO, Primrose JN, Euan TW, Finch-Jones M, Jaeck D, Mirza D, Parks RW, Collette L, Praet M, Bethe U, Van Cutsem E, Scheithauer W, Gruenberger T. FFCD EGTCCRUA-CA (2008) Perioperative chemotherapy with FOLFOX4 and surgery versus surgery alone for resectable liver metastases from colorectal cancer (EORTC Intergroup trial 40983): a randomised controlled trial. Lancet 371(9617): 1007-1016

O'Connor JP, Rose CJ, Jackson A, Watson Y, Cheung S, Maders F, Whitcher BJ, Roberts C, Buonaccorsi GA, Thompson G, Clamp AR, Jayson GC, Parker GJ (2011) DCE-MRI biomarkers of tumour heterogeneity predict CRC liver metastasis shrinkage following bevacizumab and FOLFOX-6. Br J Cancer 105(1): 139-145

Pamecha V, Nedjat-Shokouhi B, Gurusamy K, Glantzounis GK, Sharma D, Davidson BR (2008) Prospective evaluation of two-stage hepatectomy combined with selective portal vein embolisation and systemic chemotherapy for patients with unresectable bilobar colorectal liver metastases. Dig Surg 25 5: 387-393

Rehman S, Jayson GC (2005) Molecular imaging of antiangiogenic agents. Oncologist 10(2): 92-103

Riedl CC, Akhurst T, Larson S, Stanziale SF, Tuorto S, Bhargava A, Hricak H, Klimstra D, Fong Y (2007) 18F-FDG PET scanning correlates with tissue markers of poor prognosis and predicts mortality for patients after liver resection for colorectal metastases. J Nucl Med 48(5): $771-775$

Saltz LB, Clarke S, Diaz-Rubio E, Scheithauer W, Figer A, Wong R, Koski S, Lichinitser M, Yang TS, Rivera F, Couture F, Sirzen F, Cassidy J (2008) Bevacizumab in combination with oxaliplatin-based chemotherapy as first-line therapy in metastatic colorectal cancer: a randomized phase III study. J Clin Oncol 26(12): 2013-2019

Scheele J, Altendorf-Hofmann A (1999) Resection of colorectal liver metastases. Langenbeck Arch Surg 384(4): 313-327

Shih T, Lindley C (2006) Bevacizumab: an angiogenesis inhibitor for the treatment of solid malignancies. Clin Ther 28(11): 1779-1802

Therasse P, Arbuck SG, Eisenhauer EA, Wanders J, Kaplan RS, Rubinstein L, Verweij J, Van Glabbeke M, van Oosterom AT, Christian MC, Gwyther SG (2000) New guidelines to evaluate the response to treatment in solid tumors. J Natl Cancer Inst 92(3): 205-216

Tofts PS, Brix G, Buckley DL, Evelhocj JL, Henderson E, Knopp MV, Larrson HBW, Lee T-Y (1999) Estimating kinetic parameters from dynamic contrast-enhanced T1-weighted MRI of a diffusable tracer: standardized quantities and symbols. J Magn Reson Imaging 10: 223-232

Togo S, Nagano Y, Masui H, Tanaka K, Miura Y, Morioka D, Endo I, Sekido $\mathrm{H}$, Ike H, Shimada H (2005) Two-stage hepatectomy for multiple bilobular liver metastases from colorectal cancer. Hepato-gastroenterology 52(63): 913-919

Vriens D, van Laarhoven HWM, van Asten JJA, Krabbe PFM, Visser EP, Heerschap A, Punt CJA, de Geus-Oei LF, Oyen WJG (2009) Chemotherapy response monitoring of colorectal liver metastases by dynamic GdDTPA-enhanced MRI perfusion parameters and 18F-FDG PET metabolic rate. I Nucl Med 50(11): 1777-1784

Wedam SB, Low JA, Yang SX, Chow CK, Choyke P, Danforth D, Hewitt SM, Berman A, Steinberg SM, Liewehr DJ, Plehn J, Doshi A, Thomasson D, McCarthy N, Koeppen H, Sherman M, Zujewski J, Camphausen K, Chen H, Swain SM (2006) Antiangiogenic and antitumor effects of bevacizumab in patients with inflammatory and locally advanced breast cancer. J Clin Oncol 24(5): 769-777

Wicherts DA, Miller R, de Haas RJ, Bitsakou G, Vibert E, Veilhan LA, Azoulay D, Bismuth H, Castaing D, Adam R (2008) Long-term results of two-stage hepatectomy for irresectable colorectal cancer liver metastases. Ann Surg 248(6): 994-1005

This work is published under the standard license to publish agreement. After 12 months the work will become freely available and the license terms will switch to a Creative Commons Attribution-NonCommercial-Share Alike 3.0 Unported License. 